\title{
Tecnologias Digitais no Currículo da Graduação em Matemática da UEMS Nova Andradina ${ }^{1}$
}

Digital Technologies In The Curriculum Of Undergraduate Mathematics Course at UEMS Nova Andradina Tecnologías Digitales En El Currículo de Graduación En Matemáticas de UEMS Nova Andradina

\section{KARLA JOCELYA NONATOํ, NIELCE MENEGUELO LOBO DA COSTA²}

${ }^{1}$ Universidade Anhanguera de São Paulo - UNIAN

${ }^{2}$ Universidade Anhanguera de São Paulo - UNIAN

RESUMO: Na era digital é imprescindivel integrar as Tecnologias Digitais de Informação e Comunicação (TDIC) aos currículos dos cursos de formação iniciais de professores. Este artigo relata uma pesquisa documental cujo objetivo foi investigar como as TDIC são integradas no curriculo do curso de Licenciatura em Matemática da Universidade Estadual de Mato Grosso do Sul (UEMS), campus de Nova Andradina-MS, diante da cultura digital, visando a construção de um web curriculo. Os dados foram coletados a partir de informaçôes disponibilizadas no site da UEMS e no Projeto Pedagógico Curricular do curso. A análise revelou que o currículo foi reformulado para atender a Res. CNE $n^{\circ} 02 / 2015$, separando a carga horária da Prática como Componente Curricular dos Estágios Supervisionados. Concluimos que as transformacõoes empreendidas, viabilizam a construção de um web curriculo, pela inserção das TDIC em toda a proposta curricular.

FORMAÇÃO DE PROFESSORES; GRADUAÇÃO EM MATEMÁTICA; TDIC WEB CURRÍCULO.

\begin{abstract}
In the digital age, it is essential to integrate Digital Information and Communication Technologies (DICT) into the curricula of initial educational teacher courses. This article reports a documentary research whose objective was to investigate how DICT are integrated into the curriculum of the Mathematics Graduate course at the State University of Mato Grosso do Sul (UEMS), campus of Nova Andradina, in the face of digital culture, aiming at building a web curriculum. Data were collected from information made available on the UEMS website and from the Curricular Pedagogical Project of the course. The analysis revealed that the curriculum was reformulated to attend the Res. CNE $n^{\circ} 02 / 2015$, separating the workload of the Practice as Curricular Component of the Supervised Internships. We conclude that the transformations undertaken, make possible the construction of a web curriculum, through the insertion of DICT in the entire curriculum proposal.

TEACHER EDUCATION; UNDERGRADUATE MATHEMATICS COURS; DICT; WEB CURRICULUM.
\end{abstract}

\footnotetext{
1 Versão ampliada do resumo expandido apresentado no XIV EDUCON intitulado "TDIC no Currículo de Licenciatura em Matemática: o caso da UEMS de Nova Andradina".

As autoras cedem à Revista Internacional Educon os direitos de primeira publicação do presente artigo. Aplicam-se os termos de uma licença Creative Commons Atribuição 4.0 Internacional (CC BY 4.0), que permite o uso irrestrito, a distribuição e a reprodução em qualquer meio desde que a publicação original seja corretamente citada.
} 
RESUMO: En la era digital, es fundamental que se integren las Tecnologias Digitales de Información y Comunicación (TDIC) en los curriculos de los cursos de formación docente. Este articulo reporta una investigación cuyo objetivo fue indagar cómo los TDIC se integran en lo currículo de la carrera de Matemáticas de la Universidad Estatal de Mato Grosso do Sul (UEMS), campus de Nova Andradina$M S$, frente a la cultura digital, con mirar a construir uno curriculo web. Los datos se obtwieron a partir de la información disponible en el sitio web de la UEMS y analizó el Proyecto Pedagógico Curricular del curso. El análisis reveló que el currículo fue reformulado para cumplir con la Res. CNE ño2/2015, separando las horas de Práctica como Componente Curricular de Prácticas Supervisadas. Concluimos que las transformaciones emprendidas, hazlo posible la construcción del curriculo web, ya que la inserción del TDIC se da en toda la propuesta curricular.

\section{FORMACIÓN DE PROFESORES; GRADUACIÓN EN MATEMÁTICAS;} TDIC; CURRÍCULO WEB.

\section{Introdução}

A tecnologia está presente no nosso cotidiano, isto é inegável. Vivemos na era digital, em uma sociedade na qual as relações humanas são, muitas vezes, mediadas pelas tecnologias e comunicações digitais.

Os professores costumam ser usuários das Tecnologias Digitais de Informação e Comunicação (TDIC) no seu cotidiano, também normalmente utilizam as TDIC para prepararem aulas, mas pesquisadores, tais como Coutinho (2011) afirmam ser raro as usarem para ensinar e para a interação com os alunos em sala de aula. Esta realidade foi alterada drasticamente com a pandemia do novo coronavírus em 2020. A pandemia escancarou a necessidade de integração das TDIC nos processos de ensino e de aprendizagem e o quanto os professores não se sentem preparados para fazê-la (Oliveira et al, 2020)

Pesquisadores como Almeida e Valente (2011) entre outros, já apontavam para a necessidade e a importância de os professores fazerem uso pedagógico das TDIC, aprimorando e diversificando os processos de ensino e de aprendizagem. Para que, a tecnologia fosse integrada ao processo de ensino, saber como utilizá-la deve fazer parte do rol de conhecimentos do professor, assim como o conhecimento do conteúdo, no nosso caso, a Matemática. A pandemia revelou a limitação no conhecimento tecnológico pedagógico dos professores.

Abboud-Blanchard (2014) ilustra as dificuldades de integração das tecnologias, enquanto Araújo (2015) aponta que, apesar de os professores, especialmente os mais jovens, serem hábeis ao utilizarem recursos tecnológicos nas suas rotinas sociais, com frequência eles têm dificuldade em integrar as TDIC ao cotidiano das salas de aulas. A pesquisadora destaca que os professores reconhecem a importância das tecnologias digitais nos currículos, mas que essa discussão nem sempre faz parte das práticas curriculares na Universidade nos cursos em que foram formados.

Nos cursos de licenciatura a dicotomia entre teoria e prática tem sido constantemente apontada por diversos pesquisadores como um elemento dificultador na formação inicial docente. Nos anos 70, Araújo (1979 apud Fiorentini, 2002) já apontava a necessidade de romper essa dicotomia entre a teoria e a prática nas licenciaturas, o que foi retomado por Tancredi (1995, apud Fiorentini, 2002) e, também, por Figueiredo (2015) o qual enfatizou a importância da integração teoria/prática nas disciplinas específicas e pedagógicas.

Essa dicotomia entre prática e teoria na formação inicial dificulta a composição da prática didática dos futuros docentes. É preciso diminuir "o distanciamento entre o que os licenciandos aprendem e o que vivenciam na prática docente", como destaca Nonato (2011, p. 42). Lopes (2010) enfatiza que esse distanciamento também acontece com as TDIC, apontando que falta articulação entre a teoria e a prática para o uso das TDIC em sala de aula, ou seja, o currículo praticado no curso não espelha o currículo prescrito. 
Os Projetos Pedagógicos dos cursos de licenciatura podem não acompanhar a velocidade com que as tecnologias digitais evoluem ou, ainda, podem não integrar as TDIC aos seus currículos, mas a formação ofertada deve preparar o futuro professor para utilizar a tecnologia na aprendizagem da Matemática e para ensinar com tecnologia (Viseu \& Leite, 2019). Tais considerações nos levam às seguintes inquietações: Será que a sala de aula das universidades, durante a formação inicial dos futuros professores de Matemática, explora a integração das TDIC nos processos de ensino e de aprendizagem? Os Projetos Pedagógicos dos cursos conseguem acompanhar o dinamismo de transformação das TDIC?

A partir do contexto apresentado e dessas indagações, nos propusemos a seguinte questão de pesquisa: Como a unidade universitária de Nova Andradina organiza seu Projeto Pedagógico Curricular (PPC) diante dos avanços tecnológicos na Educação?

Para entender como está acontecendo a formação inicial dos futuros professores de Matemática da unidade universitária de Nova Andradina da Universidade Estadual do Mato Grosso do Sul (UEMS) analisamos o currículo do curso de Licenciatura em Matemática. Consideramos o currículo como sendo gerador de um processo ativo que envolve toda a multiplicidade de relações, das práticas pedagógicas e de decisões administrativas, como indica Sacristán (2013). A partir dessa análise identificamos as ideias fundantes na construção do PPC, as modificações do documento ao longo do tempo e se contempla a integração de recursos tecnológicos aos conteúdos curriculares.

O curso de Licenciatura em Matemática da Unidade Universitária de Nova Andradina da Universidade Estadual de Mato Grosso do Sul (UEMS) indica em seu PPC que intenciona "romper com a dicotomia entre teoria e prática." (UEMS, 2019, p. 13), inclusive a tecnológica. O currículo do curso passou por mudanças, o que justifica o interesse em pesquisar a proposta de integração das tecnologias digitais a ele.

Neste texto, o objetivo é identificar como a Graduação em Matemática da UEMS de Nova Andradina integra as TDIC ao currículo, diante da cultura digital e visando à construção de um web currículo, tendo em vista, especialmente, o fato de o Projeto Pedagógico de Curso (PPC) ter começado a vigorar no ano de 2020 .

\section{O Contexto Da UEMS Em Nova Andradina}

De acordo com o Instituto Brasileiro de Geografia e Estatística (IBGE), o estado de Mato Grosso do Sul está entre os menos populosos do Brasil com uma densidade demográfica de 6,86 hab./km2. A população estimada do estado é de 2.809.394 habitantes ( $\mathrm{O}$ último censo populacional no Brasil foi realizado em 2010, desta forma, nos referimos aos dados estimados disponibilizados no site IBGE: https://cidades.ibge.gov.br/brasil/ms/panorama), dos quais, pouco mais de um terço concentra-se na capital, Campo Grande, considerada a única cidade grande do estado (IPEA, 2008).

O Instituto de Pesquisa Aplicada (IPEA), considera como pequena as cidades com menos de 100 mil habitantes. Dos 79 municípios de Mato Grosso do Sul, somente a capital e mais três munícipios (Dourados, Três Lagoas e Corumbá) contabilizam acima desta margem. Mas, o IPEA pontua, que nas regiões Norte e Centro-Oeste, "devido às características do sistema urbano regional" (https://web.archive.org/web/20090819081149/http://www.ipea.gov.br/003/00301009.jsp?ttCD_C HAVE=5499), municípios menores, como Nova Andradina, com população entre 50 e 100 mil habitantes já desempenham a função econômica de cidades médias.

Nova Andradina tem uma população estimada em 55.224 habitantes (IBGE), figurando como uma das maiores cidades do Estado. Foi fundada pelo pecuarista paulista Antônio Joaquim de Moura Andrade, em 20 de dezembro de 1958, quando o estado ainda era Mato Grosso. O nome foi inspirado pela cidade de Andradina, em São Paulo, também fundada pelo pecuarista. 


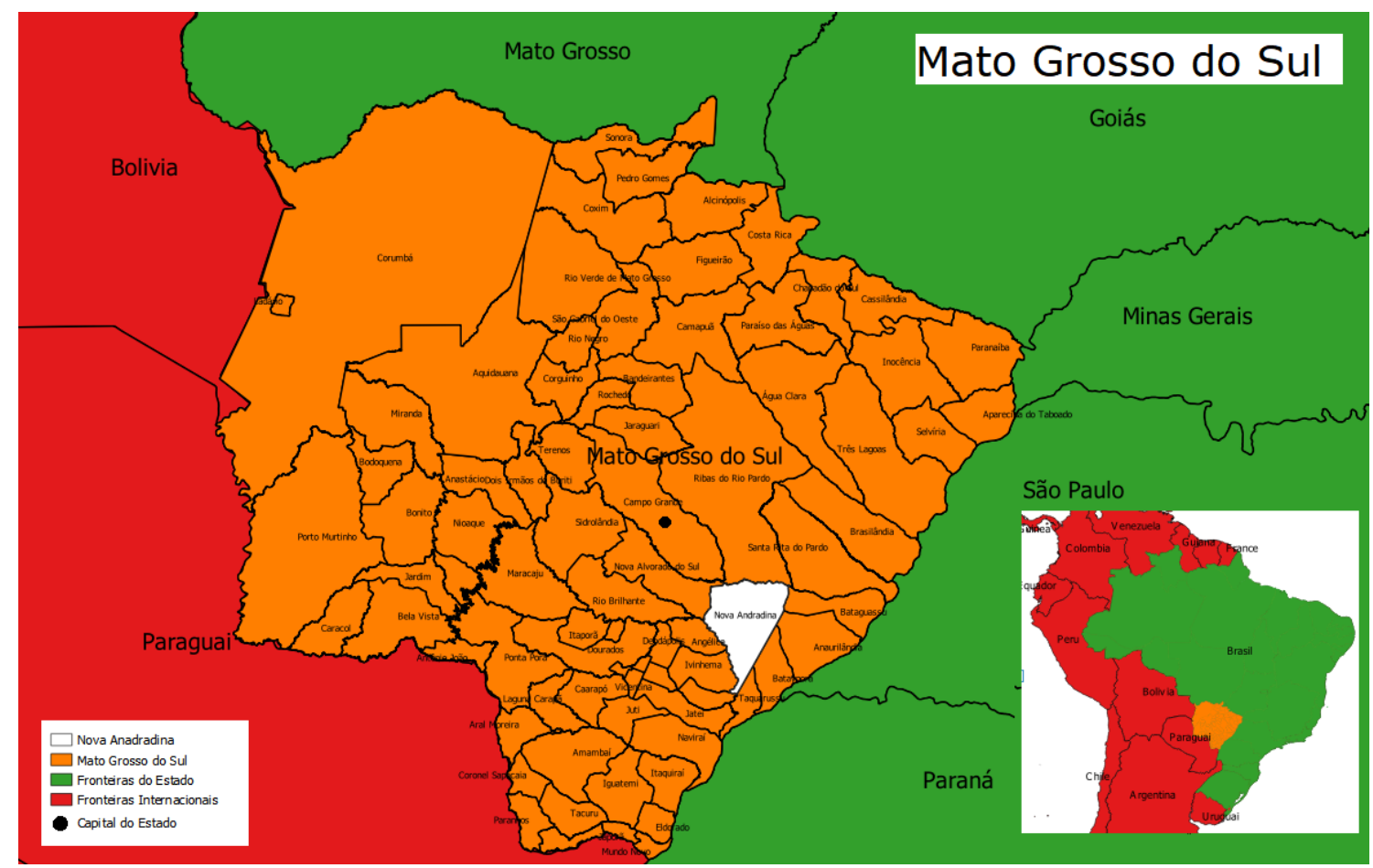

Figura 1: Imagem do Estado do Mato Grosso do Sul - cedida por Julianna Colares Rodrigues

De acordo com a Prefeitura Municipal de Nova Andradina (https://www.pmna.ms.gov.br/paginas/a-cidade/a-cidade), a posição geográfica privilegiada da cidade, no sudeste do estado, na confluência dos estados de Mato Grosso do Sul, São Paulo e Paraná, contribuiu para a expansão econômica, principalmente na criação e abate de bovinos. A economia e a cultura da cidade dependem da agropecuária, os habitantes estão muito envolvidos com essas atividades e as pessoas estudam enquanto existe oferta nas proximidades (Gomes, 2016).

As cidades do interior do Mato Grosso do Sul possuem uma forte relação com o campo, assim, a modernização do agronegócio, com a incorporação da ciência e tecnologia, afeta as relações de produção e de mão-de-obra, causando "um processo de expropriação" (Santana \& Calixto, 2019, p. 53), ou seja, cidades como Nova Andradina se tornam receptoras dos trabalhadores excedentes do campo que se convertem em mão-de-obra barata para outros serviços sem qualificação.

Na porção sudeste do estado de Mato Grosso do Sul, Nova Andradina é a cidade central na rede urbana em que está inserida. Assim, nesta nova realidade, com a tecnologia se fazendo presente em todas as áreas, o município vem assumindo novas funções também no provimento de vagas no Ensino Superior, "sua centralidade, na oferta desse serviço, se reforçou por meio da ampliação das escalas geográficas.” (Santana \& Calixto, 2019, p. 57)

Com a crescente demanda de Ensino Superior, instituições particulares, oferecendo cursos nas modalidades presencial e a distância, se instalaram na cidade, além de instituições públicas, tais como o Instituto Federal de Mato Grosso do Sul (IFMS). Houve também ampliação na oferta de cursos de graduação pela Universidade Federal de Mato Grosso do Sul (UFMS).

Os cursos da UFMS foram ampliados devido ao Programa de Reestruturação e Expansão das Universidades Federais (REUNI)², que também contemplou a cidade com o IFMS ofertando cursos

2 Instituído pelo Dec. Nº 6096/2007, o REUNI é uma das ações do Plano de Desenvolvimento da Educação (PDE). Constitui-se de um Programa de apoio com o objetivo de ampliar o acesso e a permanência na Educação Superior. (http://reuni.mec.gov.br/o-que-e-o-reuni) 
técnicos, de qualificação profissional, graduação e pós-graduação, além da modalidade de Educação a Distância para uma graduação e duas qualificações profissional.

A UEMS, instalada na cidade desde 1998, foi criada para atender demandas regionais, tendo a vocação voltada para a disseminação do ensino superior no interior do Estado (Nonato, 2011), além de se preocupar "particularmente com os altos índices de professores em exercício sem a devida habilitação, e com o desenvolvimento técnico, científico e social do Estado." (UEMS, 2010). Um dos diferenciais da UEMS é a rotatividade dos cursos, ou seja, os cursos são permanentes, mas suas localizações são temporárias (Figueiredo, 2015). Em Nova Andradina, a UEMS oferta, atualmente, os cursos de Licenciatura em Matemática e Computação.

O agronegócio vem se expandindo consideravelmente na região, o que reflete nos cursos ofertados pelas instituições federais, para atender a demanda por conhecimento especializado. No IFMS, a maioria dos cursos, sejam eles técnicos ou de graduação, são voltados para o agronegócio.

Nos cursos da UEMS essa vinculação com a economia regional não é explicita. No caso, a Universidade foi concebida com "o objetivo de desenhar um novo cenário educacional no Estado, uma vez que este tinha sérios problemas com relação ao ensino fundamental e médio, principalmente quanto à qualificação de seu corpo docente." (site da UEMS).

A cidade conta com a oferta de 5 cursos de licenciatura, entre eles o curso de Matemática na unidade universitária da UEMS, que foi implantada no ano de 1998, como Ciências, habilitação em Matemática, juntamente com Letras - Inglês, curso este que posteriormente (2010) foi transferido para a unidade universitária de Campo Grande.

No projeto analisado, implantado na UEMS em 2020, o curso de Licenciatura em Matemática, em Nova Andradina, oferece 40 vagas com ingresso via Sistema de Seleção Unificada (SiSU), no período noturno, de forma presencial e anual, a partir de 2021 o ingresso sofrerá mudanças e $50 \%$ das vagas passarão a ser preenchidas via vestibular próprio (site da UEMS). O curso tem uma carga horária total de 3.306h, distribuídas em 4 anos, com período máximo de integralização de 7 anos. Este é o cenário no qual está inserido o curso, cujo PPC analisamos. Tal PPC foi implementado na UEMS em um ano repleto de mudanças devido a pandemia do novo coronavírus.

\section{O Currículo e as Tecnologias}

Ao discutir a formação inicial de professores, compreendemos que o currículo é formado pelos conteúdos e conhecimentos, mas também pelas atitudes e ações, dos professores e alunos, na dinâmica dos processos de ensino e aprendizagem (Sacristán, 2013). Isso significa dizer que o currículo é construído socialmente, historicamente, em um processo dinâmico de disputas por território e poder. (Arroyo, 2013).

O currículo "adquire forma e significado educativo à medida que sofre uma série de processos de transformação dentro das atividades práticas" (Sacristán, 2000, p. 09) e seus requisitos de desenvolvimento e realidade devem ser entendidos em conjunto, esse conjunto incluí o contexto cultural.

Considerando o contexto cultural, de avanços tecnológicos, não faz sentido constantes adequações de conteúdos "sem mudanças de procedimentos", pois, "existe uma tendência a centrar no currículo as possibilidades de reformas qualitativas em educação". (Sacristán, 2000, p. 09).

Os PPC dos cursos de licenciatura não caminham no mesmo passo que o desenvolvimento da sociedade, especialmente quanto à evolução das TDIC, o que torna emergente a necessidade de refletirmos sobre os seus currículos. Em nosso entender, os cursos de formação inicial dos futuros professores devem ampliar, em termos conceituais e práticos os currículos, enfatizando e problematizando a experiência docente e a prática pedagógica. Um currículo fundamentado no contexto profissional e social, que se estrutura como uma trama permeável na qual podem se tecer uma multiplicidade de conhecimentos, incluindo os tecnológicos e assim, adequando conteúdos e procedimentos. 
As tecnologias e as TDIC fazem parte do nosso cotidiano, e deveriam ter lugar no currículo da formação inicial de professores, pois este envolve muito mais do que conhecimentos técnicos, devendo criar oportunidades para o futuro professor contextualizar e recontextualizar o aprendizado e a experiência vivida como aluno da Educação Básica e durante a formação na universidade construir referenciais para a sua futura realidade. Nessa contextualização/recontextualização do aprendizado/experiência, o licenciando deve atribuir sentido ao uso das TDIC em sua prática, integrandoas ao seu fazer docente, de modo que contribuam nos processos de ensino e de aprendizagem (Almeida, 2016), assim como atribui sentido ao uso das tecnologias, de forma geral.

As tecnologias são as ferramentas utilizadas pelos professores para que os alunos aprendam, assim, até o giz que ele usa é uma tecnologia de comunicação (Lobo da Costa \& Prado, 2015) e as ferramentas utilizadas cotidianamente pelos professores fazem sentido no processo de ensino e de aprendizagem, assim como deveria ocorrer com as tecnologias digitais, "representadas por distintos dispositivos tecnológicos com características de mobilidade e conexão à internet" (Almeida, 2014, p. 21), que se fazem presente no nosso cotidiano.

Essa mudança no percurso do currículo, utilizando a tecnologia digital integrada ao ensino, aproxima-se do conceito de web currículo, definido por Almeida (2014, p. 26) como sendo:

o currículo que se desenvolve com a midiatização de ferramentas e interfaces das TDIC e se organiza em redes hipertextuais abertas ao estabelecimento de arcos, que criam novas ligações entre nós já estabelecidos, constituídos por informações e também por novos nós que integram conhecimentos previamente elaborados e conhecimentos em construção pelos aprendizes (estudantes, professores e outras pessoas).

A proposição de um web currículo exige reflexões a respeito das propostas pedagógicas desenvolvidas integrando as TDIC ao ensino para promover a aprendizagem, isto significa mais do que simplesmente usar o computador ou tablet nas aulas. Acreditamos que este é um tipo de currículo necessário para os cursos de formação de professores diante da revolução digital que estamos vivendo, em particular, os de licenciatura em Matemática.

Para criar um web currículo, além dos professores, alunos, TDIC e da proposta curricular, é necessária uma prática pedagógica que se fortaleça por meio de projetos, de investigação cientifica e resolução de problemas. O diferencial está na prática pedagógica, que deve integrar e não simplesmente inserir as TDIC, "impulsionando o pensar coletivo, a produção compartilhada e a democratização do conhecimento." (Almeida, 2014, p. 27).

Ao desenvolver o web currículo, novos conhecimentos e habilidades são construídos, ao fazer uso de várias mídias há a possibilidade de expressar e produzir conhecimentos diferentemente do que ocorre na simples adição de " $2+2$ ", o ensino exige que professores formadores e licenciandos dominem os recursos tecnológicos para construírem os conhecimentos necessários aos processos de ensino e de aprendizagem.

Diante deste cenário a formação do professor muda, ele deve participar de um processo de formação na ação no qual tenha a oportunidade de explorar as TDIC em sua própria aprendizagem, identificar as contribuições dessas tecnologias ao ensino, à aprendizagem e ao currículo, utilizá-las em experiencias com seus alunos [...] e reconstruí-las. (Almeida, 2014, p. 29)

A formação torna-se um modelo para a prática pedagógica do futuro professor, que assim será voltada para a integração das tecnologias ao currículo e quiçá à criação de web currículo, sendo o currículo prescrito (que se apresenta em forma de documentos) e o currículo praticado (que realmente se desenvolve no curso) ficando mais próximos, evocando à integração das tecnologias. 


\section{Configurações da Pesquisa}

Diante das indagações e reflexões expostas, a pesquisa configurou-se com a metodologia qualitativa, concordamos com Gibbs (2009), quando o autor pontua que está cada vez mais difícil chegar a uma definição de pesquisa qualitativa que seja aceita pela maioria dos pesquisadores. A pesquisa qualitativa desenvolveu identidade própria, e assim, declaramos que nossa pesquisa é qualitativa, pois os dados colhidos no currículo são em forma de palavras, além de dedicar-se a interpretar aspectos do processo de formação dos licenciandos (Bodgan \& Biklen, 1994).

Considerando que o currículo é mais do que um rol de conteúdos, sendo um conjunto denso de dados, optamos por analisar o PPC do curso de Licenciatura em Matemática da UEMS. O PPC expõe o currículo prescrito, é um documento do curso o que, quanto aos meios, insere a pesquisa na análise documental (Cellard, 2008).

Por sua vez, o currículo prescrito, como documento, adquire "forma e significado educativo", o que nos levou a optar pela análise interpretativa, que, de acordo com Severino (2007) respeita as ideias enunciadas, mas lê nas entrelinhas, como se dialogasse com o autor. Em particular, a análise interpretativa atende as características da hermenêutica de profundida (Thompson, 2011), já que a fase denominada análise sócio-histórica foi contemplada ao retratarmos as situações no espaço e no tempo, analisando o conjunto de relações que a Instituição constitui, caracterizando os sujeitos que nela atuam (alunos e moradores da região), envolvendo a estrutura social que a integra.

Posteriormente realizamos a fase da análise interpretativa/re-interpretativa dos dados da hermenêutica de profundidade, partindo das categorias pré-estabelecidas pelo PPC na matriz curricular, antes de apresentar as categorias, interpretamos todas a parte textual do PPC, que a antecede. Para a análise partimos das categorias pré-estabelecidas pelo próprio PPC para a matriz curricular, quais sejam: "Núcleo de Formação Geral" (NFG), "Núcleo de Aprofundamento e Diversificação" (NAD), "Disciplinas de Formação Pedagógicas" (DFP) e "Núcleo de Estudos Integradores e outras componentes curriculares".

A UEMS oferta o curso de Licenciatura em Matemática nas unidades universitárias de Dourados, Cassilândia e de Nova Andradina. Neste texto, nos debruçamos sobre o PPC da unidade universitária de Nova Andradina (PPC-NA). A coleta de dados foi realizada a partir de documentos públicos, que está disponível na página do curso, no site da UEMS (http://www.uems.br/nova andradina). Ele é composto por: Regimento da UEMS, Resolução CEPE-UEMS n ${ }^{\circ} 1.238 / 2012$ e pela Portaria PROE-UEMS $n^{\circ}$ 70/2019.

$\mathrm{Na}$ próxima seção expomos as características da Licenciatura em Matemática da unidade universitária de Nova Andradina da UEMS, para posteriormente apresentar os resultados da análise documental.

\section{Licenciatura em Matemática na UEMS de Nova Andradina}

A Licenciatura da UEMS/Nova Andradina tem seriação anual e é regida pela Resolução CNE 02/2015 (Brasil, 2015) que aponta, entre outros, o objetivo de preparar um profissional que tenha a formação voltada ao uso das TDIC.

A partir de 2020 está sendo implementado um novo projeto para o curso de Matemática, em substituição ao que esteve vigente de 2011 a 2019. Ele foi denominado de PROJETO PEDAGÓGICO CURRICULAR Curso de Licenciatura em Matemática - Nova Andradina (PPC-NA).

Destacamos que entendemos currículo como "uma construção social do conhecimento, pressupondo a sistematização dos meios para efetivá-la e envolve a difusão de conhecimentos historicamente produzidos e as formas de assimilá-los." (Veiga, 1995, p. 07). Currículo vai além dos conteúdos programáticos, considerando a intervenção ativa do professor para sua efetivação. (Sacristán, 
1998). Entretanto, a análise desse PPC-NA está centrada nos conteúdos programáticos, os quais são denominados institucionalmente por "currículo" ou "estrutura curricular".

O curso segue as orientações gerais da UEMS que, por sua vez obedecem às orientações nacionais para elaboração do seu PPC, tais como a Res. CNE no 02/2015, buscando colocar "os egressos no mercado de trabalho tão logo terminam o curso, na espera que possam contribuir na melhoria da qualidade do Ensino Básico.” (UEMS, 2019, p. 05).

\subsection{Projeto Pedagógico Curricular - Nova Andradina}

O PPC-NA analisado foi reformulado pela deliberação CE-CEPE no 297, de 26 de junho de 2019, homologado, com alterações, pela resolução $\mathrm{n}^{\circ} 2.102$, de 24 de outubro de 2019 e entrou em vigor em 2020. Foi alterado para atender a Resolução CNE 02/2015, adequando a oferta das "Atividades Complementares" e separando a "Prática de Ensino" do "Estágio Supervisionado".

O PPC-NA se organiza em 12 seções, a saber:

\begin{tabular}{|l|}
\hline Identificação do Curso \\
\hline Introdução \\
\hline Concepção do Curso \\
\hline Princípios Norteadores \\
\hline Estrutura Curricular do Curso \\
\hline Organização Curricular \\
\hline Resumo Geral da Matriz Curricular \\
\hline Quadro de Equivalência Curricular \\
\hline Implantação do Projeto Pedagógico do Curso \\
\hline Ementário das Disciplinas \\
\hline Referência Bibliográfica \\
\hline Apêndices \\
\hline
\end{tabular}

Quadro 1: Seções do PPC-NA, elaborado pelas autoras.

Ele foi pensado para atender também alunos com déficit de aprendizado e de baixo poder aquisitivo, uma vez que "a clientela é originária de escola pública e noturna, distante dos grandes centros, com pouco recurso financeiro, viajam grande distância para estudar e ainda com um déficit escolar" (UEMS, 2019, p. 05).

Nova Andradina faz divisa com os estados de São Paulo e Paraná e está localizada no Vale do Ivinhema, que fica no sudoeste do estado de Mato Grosso do Sul e é composto por municípios, sendo: Anaurilândia, Angélica, Bataguassu, Batayporã, Brasilândia, Ivinhema, Nova Andradina, Novo Horizonte do Sul, Santa Rita do Pardo e Taquarussu. Assim, os licenciandos são oriundos destas regiões, com características distintas e consideradas na elaboração do PPC, inclusive as características dos futuros alunos dos licenciandos, pois esses devem estar preparados para a realidade desses alunos ao adentrarem as salas de aula como profissionais da Educação.

A análise das seções de Introdução e Concepção do Curso evidenciam inicialmente a preocupação na adaptação e manutenção dos licenciando no curso, ofertando, inclusive um "processo de nivelamento" (UEMS, 2019, p. 13), ou seja, buscando a democratização da Educação de qualidade, que pode ser realizada com a integração das TDIC.

Na seção "Perfil do profissional que se pretende formar" está estabelecido que o curso busca formar um profissional com visão crítica, como evidencia o excerto a seguir: 
O profissional [...] licenciado em Matemática, deve caracterizar-se pelo domínio dos conhecimentos matemáticos, pedagógicos, e pela visão crítica da realidade em seus aspectos sociais, econômicos, culturais e políticos, de modo especial em relação às implicações que tem entre si as Ciências, a Tecnologia, a Educação e a Sociedade. (UEMS, 2019, p. 09).

Vale ressaltar que é nesse excerto que surge pela primeira vez a menção à Tecnologia como integrante dos conhecimentos profissionais para a docência e demonstra a preocupação em formar um professor preparado para integrar as TDIC ao currículo e considerar o papel da educação na vida do aluno.

Um profissional que no domínio de sua disciplina específica conheça as relações e coerência interna da própria ciência de origem, [...] e que possa levar em conta seus aspectos formativos, informáticos e práticos em um universo educacional. (UEMS, 2019, p. 09).

Assim, o PPC-NA indica no perfil profissional a expectativa de que o futuro professor faça uso das TDIC em seu cotidiano de sala de aula e esteja conectado aos instrumentos da "cultura digital". dois itens:

No tópico "Competências" (UEMS, 2019, p. 9-10) a se desenvolver nos licenciandos destacamos

- planejar, criar e adaptar métodos, procedimentos e estratégias de ensino: avaliação; currículo; objetivos; [...]

- planejar, criar e adaptar métodos, procedimentos e estratégias de ensino: avaliação; currículo; objetivos;

Embora, em qualquer deles as TDIC não apareçam explicitamente, fica subentendido, diante da análise do texto anterior, sobre o perfil profissional esperado, que o curso pretende desenvolver a competência no licenciando de usar as tecnologias digitais, isso fica evidente quando cita "adaptar métodos", caso aconteça, há indícios do web currículo, pois demonstra a preocupação com o professor "consciente da concepção de currículo" (Almeida, 2014, p. 29) e preparado para integrar as TDIC com fins pedagógicos.

Em "Habilidades", destacamos a seguinte habilidade desejada: "relacionar a linguagem dos meios de comunicação à educação, nos processos didático-pedagógicos, demonstrando domínio das tecnologias de informação e comunicação para o desenvolvimento da aprendizagem;" (UEMS, 2019, p. 11). Nesse caso, está explicitado que o licenciado deve "dominar" o uso das TDIC, preceito necessário também ao aluno para desenvolver tal habilidade é ele vivenciar um web currículo na formação inicial.

No tópico "Princípios Norteadores" o PPC-NA faz uma breve descrição das disciplinas do curso, as vezes discorrendo sobre a metodologia, as vezes sobre o que se espera dela. Nesta descrição apresentam como os "núcleos" de disciplinas são divididos. O maior núcleo é o de "disciplinas de formação geral e de aprofundamento e diversificação", que é formado pelas "disciplinas de conteúdo da área Matemática", "disciplinas que estabelecem a interface da Matemática com a Educação Matemática", "disciplinas que estabelecem a interface com outras áreas do conhecimento" e "disciplinas da área de Pedagogia".

Completando o rol de disciplinas temos: "Trabalho de Conclusão de Curso" (TCC), "Atividades Complementares" (AC) e "Estágio Curricular Supervisionado". Ainda discorrem sobre a "Prática como Componente Curricular" (PCC), que tem carga-horária distribuída nas disciplinas do primeiro núcleo, sobre as atividades de extensão universitária, que contabilizam horas nas $\mathrm{AC}$ e dois itens que nos interessam analisar mais detalhadamente na procura pela inserção/integração das TDIC: "Metodologia" e "Relação entre Ensino, Pesquisa, Extensão e a Pós-Graduação".

Este último, devido a obrigatoriedade das "Atividades de Extensão Universitária” e principalmente pelo primeiro parágrafo da descrição: 
Deverão ser oferecidas aos graduandos oportunidades de apropriarem e fazerem uso de recursos da tecnologia e da comunicação com a finalidade de ampliar seu universo cultural para que possam elaborar e desenvolver projetos pessoais de estudo e trabalho utilizando diferentes fontes e veículos de informação. (UEMS, 2019, p. 23)

A ideia é que a relação entre Ensino, Extensão e Pesquisa aconteça naturalmente em todas as graduações, ao passo que os graduandos conseguem relacionar os conceitos estudados com a solução de problemas do seu contexto profissional e sendo as "Atividades de Extensão Universitária” obrigatórias, há um currículo transformado.

Quanto à "Metodologia", trata-se de uma metodologia geral para o curso, resguardando a autonomia do professor quanto a sua disciplina e não esclarecendo a proposta de ação quanto ao uso das TDIC. Apesar disso, enfatizam a importância de acabar com a dicotomia entre a teoria a e prática, incluindo na prática, a tecnológica.

De acordo com o PPC-NA, a "Estrutura Curricular do Curso" é dividida em quatro grupos: "Núcleo de Formação Geral" (NFG), "Núcleo de Aprofundamento e Diversificação" (NAD), "Disciplinas de Formação Pedagógicas" (DFP) e "Núcleo de Estudos Integradores e outras componentes curriculares" (NEIO).

O quadro 1, a seguir, explicita cada disciplina da Estrutura Curricular do Curso e o grupo ao qual pertence, NFG, NAD, DFP e NEIO, com objetivo de síntese e visualização geral.

\begin{tabular}{|l|c|c|c|c|}
\hline Disciplinas & NFG & NAD & DFP & NEIO \\
\hline Álgebra Linear & & $\mathrm{X}$ & & \\
\hline Análise Matemática & & $\mathrm{X}$ & & \\
\hline Atividades Complementares & & & & $\mathrm{X}$ \\
\hline Atividades de Extensão Universitária & & & & $\mathrm{X}$ \\
\hline Cálculo Diferencia e Integral I & $\mathrm{X}$ & & & \\
\hline Cálculo Diferencial e Integral II & & $\mathrm{X}$ & & \\
\hline Cálculo Numérico & & $\mathrm{X}$ & & \\
\hline Didática da Matemática; e Didática Geral & $\mathrm{X}$ & & $\mathrm{X}$ & \\
\hline Estágio Curricular Supervisionado Obrigatório & & & & $\mathrm{X}$ \\
\hline Estruturas Algébricas & & $\mathrm{X}$ & & \\
\hline Filosofia, Sociologia e História da Educação & $\mathrm{X}$ & & $\mathrm{X}$ & \\
\hline Física I e II & $\mathrm{X}$ & & & \\
\hline Geometria; e Geometria Analítica & $\mathrm{X}$ & & & \\
\hline História da Matemática & $\mathrm{X}$ & & & \\
\hline Informática no Ensino de Matemática & $\mathrm{X}$ & & $\mathrm{X}$ & \\
\hline Laboratório de Ensino de Matemática & $\mathrm{X}$ & & $\mathrm{X}$ & \\
\hline Legislação e Política Educacional Brasileira & $\mathrm{X}$ & & $\mathrm{X}$ & \\
\hline LIBRAS; e Língua Portuguesa & $\mathrm{X}$ & & & \\
\hline Matemática Elementar & $\mathrm{X}$ & & & \\
\hline Metodologia de Investigação em Educação Matemática & $\mathrm{X}$ & & $\mathrm{X}$ & \\
\hline Psicologia da Educação & $\mathrm{X}$ & & $\mathrm{X}$ & \\
\hline Probabilidade e Estatística & & $\mathrm{X}$ & & \\
\hline Trabalho de Conclusão de Curso & & & & $\mathrm{X}$ \\
\hline
\end{tabular}

Quadro 1: Disciplinas do PPC-NA e respectivos grupos da Estrutura Curricular, elaborado pelas autoras.

Observamos que existem disciplinas que integram dois dos grupos, sendo do NFG e do DFP. As disciplinas destes grupos tiveram as 400h de "Prática como Componente Curricular" (PCC) distribuídas entre elas. Todas tiveram o acréscimo de 34h de PCC, exceto "Laboratório de Ensino de Matemática" 
que tem 102h de PCC, são elas: "Matemática Elementar", "Cálculo Diferencial e Integral I", "Geometria", "Filosofia, Sociologia e História da Educação", "Física I", "Informática no Ensino de Matemática", "Metodologia de Investigação em Educação Matemática", "Psicologia da Educação", "Física II", "Didática da Matemática", "Didática Geral" e "História da Matemática".

As disciplinas do Núcleo de Formação Geral (NFG) corresponde ao que o nome diz, pois há disciplinas de caráter matemático (Geometria e Matemática Elementar, por exemplo), de caráter pedagógico (Didática Geral), que inclusive integra o grupo de DFP, da área de Educação Matemática (História da Matemática), englobando a tecnologia (Informática no Ensino de Matemática), as Ciências Socias (Filosofia, Sociologia e História da Educação) e linguagem (Língua Portuguesa), entre outros.

Nas Disciplinas de Formação Pedagógica (DFP), o grupo destina-se a construir e aprofundar o conhecimento pedagógico dos licenciandos, fazendo elos com o conhecimento do conteúdo e tecnológico, visível na disciplina de Informática no Ensino de Matemática (analisaremos com mais detalhes adiante).

No Núcleo de Aprofundamento e Diversificação (NAD) há presença apenas de disciplinas da área de Matemática, supondo que para ensinar Matemática o aprofundamento necessário seja nesta área ou em ou áreas afins, desconsiderando os conhecimentos advindos da área da Educação Matemática.

O "Núcleo de Estudos Integrados e Outros componentes curriculares" (NEIO) apresenta uma subdivisão. A "Atividades Complementares" como do Núcleo de Estudos Integrados e o "Estágio Curricular Supervisionado Obrigatório", "Trabalho de Conclusão de Curso" e "Atividades de Extensão Universitária" como Outros componentes curriculares.

Apresentada a "estrutura curricular do curso", analisamos, na sequência as ementas e seus objetivos. Identificamos e discutimos as disciplinas nas quais existe menção ao uso das TDIC.

As ementas das disciplinas de conhecimento matemático, não mencionam procedimentos metodológicos e, sequer a possibilidade do uso de softwares para o seu ensino, tendo em suas bibliografias clássicos incontestáveis das respectivas áreas. As exceções são as disciplinas de "Probabilidade e Estatística" e "Cálculo Numérico".

"Probabilidade e Estatística" apresenta uma ementa clássica e nos objetivos, constatamos a ênfase em "Possibilitar condições de utilizar ferramentas e a teoria do conhecimento de estatística nas aplicações e na pesquisa matemática.” (UEMS, 2019, p. 55), o que explicita a importância da vinculação teoriaprática. A descrição da disciplina aponta como "sendo fundamental o uso de softwares." (UEMS, 2019, p. 15) para "a construção de um repertório básico de conhecimento das Ciências Sociais" (IBID). Esses dizeres permitem identificar a presença de TDIC nos conteúdos a se discutir na disciplina. Além disso, na Bibliografia complementar, apresenta uma obra de Estatística para Informática, a saber: "BARBETTA, P. A.; REIS, M. M.; BORNIA, A. C. Estatística para cursos de Engenharia e Informática, São Paulo. Atlas, 2004." A integração das TDIC pode ocorrer centrada nos objetivos e associada ao ensino com métodos instrucionais, se configurando como um "currículo centrado em prescrições" (Almeida, 2014, p. 24).

Já o Cálculo Numérico, tem por objetivo: "Resolver, computacionalmente, problemas explorando dificuldades e soluções para a obtenção de tentativas iniciais, aceleração de convergência e acesso à precisão do resultado obtido." (UEMS, 2019, p. 36). A disciplina apresenta as TDIC de forma explicita e uma "Bibliografia Básica" voltada para o uso de tecnologias, a saber:

ARENALES, S.; DAREZZO A. Cálculo numérico: aprendizagem com apoio de software. São Paulo. Editora Pioneira Thomson Learning. 2008.

RUGGIERO, M. G.; LOPES, V. L. Cálculo numérico: aspectos teóricos e computacionais. São Paulo. Makron Books. 1996.

SPERANDIO, D.; MENDES J. T.; SILVA L. H. M. Cálculo Numérico: Características Matemáticas e Computacionais dos Métodos Numéricos. São Paulo. Prentice Hall. 2003. 
Desta forma, nesta disciplina de Cálculo Numérico é necessário que o professor faça uso das TDIC no processo de ensino de forma integrada ao conteúdo. Poderá acontecer a "exploração das propriedades constitutivas" (Almeida, 2014, p. 24) das ferramentas computacionais, permitindo um currículo reconstruído na prática pedagógica, vivenciado pelos licenciandos.

"Língua Portuguesa" apresenta o seguinte item na ementa "Noções de texto convencional e hipertexto digital.", com o correspondente nos objetivos "Compreender a noção de textos convencionais e hipertexto digitais, através dos fatores que entram em sua estruturação.", trazendo a seguinte bibliografia complementar: "DIAS, M. H. P. Hipertexto - o labirinto eletrônico: uma experiência hipertextual. 2000 (Tese) Doutorado em Educação. Universidade Estadual de Campinas, Campinas SP." Vale comentar que essa disciplina não é específica do curso de Licenciatura em Matemática, mas nela está evidenciada a preocupação com a inserção/integração das tecnologias no currículo.

A disciplina de "Didática Geral" aborda temas gerais da Didática, mas também temas específicos do Ensino da Matemática, como por exemplo a Etnomatemática, o que podemos observar no excerto a seguir:

O ensino de matemática na educação básica; Teorias de ensino e aprendizagem; relação professor e aluno; aprendizagens significativas. O professor de matemática na escola pública; interdisciplinaridade, transdisciplinaridade, projetos, Etnomatemática; planejamento: currículo, objetivos, metodologias, avaliação; a aula e seu desenvolvimento. (UEMS, 2019, p. 38)

A disciplina apresenta na Bibliografia Complementar duas obras voltadas especificamente para Ensino de Matemática, são elas: “1) D’AMBRÓSIO, U. Etnomatemática: Elo entre Tradições e a Modernidade, Belo Horizonte. Autêntica. 2001. 2) Base Nacional Comum Curricular, BRASIL, 2018." A presença dessas obras, embora na bibliografia complementar, evidenciam a intenção de um ensino de Didática Geral que contemple também as especificidades de uma licenciatura em Matemática. Entretanto, em relação as TDIC, elas não aparecem explicitamente, podendo ser abordadas, por exemplo em "projetos" e em "metodologias".

Os Estágios obrigatórios são dois: "Estágio Curricular Supervisionado de Matemática no Ensino Fundamental" e "Estágio Curricular Supervisionado de Matemática no Ensino Médio". Suas ementas, objetivos e bibliografias são diferentes, mas ambos dão abertura, de forma implícita para abordar as TDIC. Entretanto, somente em: "Tendências em educação matemática" e "Tendências no ensino de matemática: matemática escolar, seus problemas e desafios." E, nos objetivos em: "Identificar as principais tendências atuais em Educação Matemática." e "Desenvolver com os acadêmicos estagiários, estudos [...], através de atividades de laboratório envolvendo situações teóricas e práticas.”. As atividades do Estágio, como referência para a prática pedagógico dos futuros professores, deveria ser voltada à integração das tecnologias ao currículo, mas, neste momento, a ideia é o licenciando aprender sobre a prática com os professores regentes das escolas, mais do que com os professores formadores da universidade (Nonato, 2011).

"Didática da Matemática" não apresenta de forma explicita qualquer relação com a tecnologia, mas no ementário está subentendido que as TDIC poderão ser discutidas em sala de aula, como por exemplo em: "Tendências atuais na formação de professores. [...] O perfil do educador matemático contemporâneo. [...] Abordagens contemporâneas do processo de ensino e aprendizagem." (UEMS, 2019, p. 37). Nos objetivos não há menções e na bibliografia, somente na complementar, quando sugere a obra de Lorenzato, "O Laboratório de Ensino de Matemática na Formação de Professores". Parte da carga horária da disciplina de "Didática da Matemática", assim como de outras disciplinas do curso, será desenvolvida de forma semipresencial, com a orientação do professor (discutiremos a diante), nesta, na descrição da disciplina, o PPC-NA a justifica pela necessidade de "manipulação de objetos matemáticos, somente possível através de objetos mediadores e do uso de novas tecnologias" (UEMS, 2019, p. 18). O uso educativo das TDIC, assim como foi apontado por Valente e Almeida (1997), não garante melhoria nos processos de ensino e de aprendizagem. 
A disciplina com maior carga horária do PPC é "Laboratório de Ensino de Matemática", com a seguinte ementa:

O Laboratório de Ensino de Matemática como apoio pedagógico à educação básica. Metodologias de ensino de Matemática e o uso de materiais e tecnologias. A Pesquisa de materiais e métodos alternativos para o ensino de Matemática. $\mathrm{O}$ uso de recursos materiais e tecnológicos para o desenvolvimento de atividades de ensino de Matemática. Desenvolver metodologias de resolução de situações-problema para o estudo dos conteúdos matemáticos. Planejamento de atividades no laboratório (elaborar e refazer objetivos relativos a um conteúdo determinado). Planejamento e apresentação de aulas simuladas com a utilização de recursos materiais e tecnológicos. A produção de materiais e métodos didático-pedagógicos para o ensino de Matemática. (UEMS, 2019, p. 49)

Observamos que a ementa é extensa, entretanto, somente um dos itens corresponde as TDIC: "Planejamento e apresentação de aulas simuladas com a utilização de recursos materiais e tecnológicos." e, ao analisarmos os objetivos, nenhum deles apresenta as TDIC explicitamente, mas de acordo com a própria descrição da disciplina,

Laboratório de Ensino de Matemática, não deve ser concebido com um local ou sala [...], mas sim uma disciplina [...] que possa promover a integração entre estudo, o ensino e a aprendizagem [...] com a contribuição das novas tecnologias para o estudo da matemática. (UEMS, 2019, p. 18)

A descrição da disciplina aponta para o desejo de ultrapassar os muros da universidade e se estender para além dos espaços e tempos destinados a aula, podendo promover a integração da educação formal (da academia) com a informal do mundo digital. Assim, concluímos que as TDIC deverão ter presença constante durante as aulas de "Laboratório de Ensino de Matemática", entretanto, tais indicações não se refletem na bibliografia básica, que é apresenta sem indícios de atividades práticas, principalmente no que diz respeito às TDIC.

Finalizando a análise das ementas, consideramos "Informática no Ensino da Matemática". Esta disciplina compõe o grupo de DFP, e sua ementa indica:

Introdução à Computação. As Tecnologias Digitais de Informação e Comunicação no processo ensino e aprendizagem de conceitos matemáticos. A aprendizagem da Matemática em ambientes informatizados. A informática como recurso auxiliar para o docente de Matemática. Análise e propostas de utilização de softwares educacionais. (UEMS, 2019, p. 48)

Ressaltamos que Introdução à Computação está inserida na ementa da disciplina, uma vez que ela objetiva "capacitar o aluno para o uso de técnicas de computação e linguagem de programação", entretanto não há detalhamento sobre o que será focado nessa Introdução. Todos os demais itens do ementário são sobre TDIC para o ensino de Matemática, contudo, as obras da bibliografia, são clássicas, somente uma é de 2017 e as outras são antigas, considerando que o PPC foi aprovado e formulado em 2019.

A disciplina de "Informática no Ensino de Matemática" é ofertada no $2^{\circ}$ ano da Graduação em Matemática, com uma ementa que oportuniza a exploração das "TDIC em sua própria aprendizagem" (Almeida, 2014, p. 29) já na primeira metade do curso, proporcionando os conhecimentos básicos para a integração das tecnologias digitais nas demais disciplinas.

As disciplinas de "Filosofia, Sociologia e História da Educação", "Metodologia da Investigação em Educação Matemática", "Psicologia da Educação", "Didática da Matemática", "Didática Geral" e "Laboratório de Ensino de Matemática" estão previstas com parte da sua cara horária à distância, ou seja, semipresencial. O PPC esclarece que essa carga horária será desenvolvida em Ambiente Virtual de 
Aprendizagem (AVA) ou por "meio de atividades orientadas pelos professores, com o uso de recursos das Tecnologias Digitais da Comunicação e Informação" (UEMS, 2019, p. 30-31).

Todo o curso oferece somente quatro disciplinas de Educação Matemática (Informática no Ensino de Matemática, Metodologia da Investigação em Educação Matemática, Didática da Matemática e Laboratório de Ensino de Matemática), três delas estão no rol das disciplinas com carga horária à distância e a única que não está é um misto com computação.

Os temas de Educação Matemática, incluindo as tecnologias digitais, são dinâmicos, há muito material novo. Os itens das disciplinas destas áreas são bem amplos, talvez para tentar acompanhar esse dinamismo, já que o PPC anterior é de 2010.

Em relação à "Organização Curricular”, as disciplinas são distribuídas em quatro séries, totalizando 3306 horas (2755 horas-aula), sendo 1842 horas (2210 horas-aula) "Teóricas" - termo constante no PPC - e 425 horas (510 horas-aula) de PCC. Além disso, há a previsão de que:

As disciplinas que estão previstas com parte de sua carga horária à distância, serão desenvolvidas em Ambiente Virtual de Aprendizagem, ou por meio de atividades orientadas pelos professores, com o uso de recursos das Tecnologias Digitais da Comunicação e Informação, ou por outros recursos didáticos, desde que aprovados pelo Colegiado de Curso e registrados nos Planos de Ensino das Disciplinas. (UEMS, 2019, p. 30)

Isso é um indício de que os licenciandos deverão desenvolver conhecimentos tecnológicos e de informática que os capacitem a utilizar as ferramentas do AVA (que não são evidenciadas no PPC-NA), frisamos que se as tecnologias digitais forem utilizadas somente como ferramenta que dão suporte ao desenvolvimento da aprendizagem, o web currículo não está sendo construído.

Outro fato a ser observado sobre as disciplinas que terão carga horária à distância, é que todas elas têm PCC, ou seja, nenhuma delas são do Núcleo de Aprofundamento e Diversidade (NAD) da qual as disciplinas de conhecimento exclusivamente matemático fazem parte.

Além disso, coincidentemente, a carga horária destinada a PCC é a mesma a ser desenvolvida à distância, ou seja, "Didática Geral", por exemplo, é uma disciplina de 102h, das quais, 68h são teóricas, 34h são de PCC e são 34h a distância, para o total de 102h, adiciona-se a carga horária teórica e a de PCC.

\section{Considerações finais}

$\mathrm{Na}$ era digital as TDIC fazem parte do cotidiano, esse cotidiano também inclui a casa, a escola e a academia. Isso faz com que conhecimentos espontâneos sobre as TDIC sejam construídos pelos indivíduos e estes devem ser considerados como conhecimentos prévios. Assim sendo, é fundamental que os professores integrem as tecnologias digitais no dia-a-dia da sala de aula, começando na formação inicial e indo para as escolas. $\mathrm{O}$ uso das TDIC nos processos de ensino e aprendizagem é uma tendência discutida constantemente. No PPC da Licenciatura em Matemática na unidade universitária de Nova Andradina o tema "Tendências atuais em Educação Matemática" apresenta diferentes roupagens, e é uma constante nas disciplinas, podendo contemplar os avanços tecnológicos na educação.

O uso ou não das TDIC durante os processos de ensino e de aprendizagem, em muitos momentos, é uma decisão do professor. O PPC analisado presa pela autonomia do professor, deixando lacunas no currículo para a inserção da tecnologia, especialmente na carga horária de PCC, a qual está diluída em 13 das 34 disciplinas no decorrer do curso.

Reconhecemos que o currículo é reconstruído na prática social com a utilização das TDIC por meio da análise dos projetos (Almeida, 2014), não entraremos na seara das escolhas e do papel do professor. Entendemos que a construção de um web currículo mostra avanços na busca pela inserção das TDIC nos processos de ensino e de aprendizagem, o PPC em questão foi analisado por este prisma. 
Uma transformação significativa vinculada as tecnologias no PPC de Nova Andradina é o desenvolvimento de parte da carga horária a distância, o que, por si só, não garante a integração das tecnologias ao curso, muito menos que um web currículo esteja sendo construído. Entendemos que este item do PPC merece uma discussão mais aprofundada, mas ficaram questionamentos que a análise documental não foi capaz de nos responder.

A PCC, diluída nas demais disciplinas do curso, tem carga horária superior a 100h em todos os anos do curso, as disciplinas que trazem o tema tecnologia de forma explicita ou implícita em suas ementas, objetivos ou descrição permeiam o curso, mas estão, em sua maioria, alocadas nos dois últimos anos do curso. Somente "Língua Portuguesa" está no primeiro ano e "Informática no Ensino de Matemática” está no segundo ano.

O currículo prescrito do curso tem temas amplos, possibilitando a escolha do professor quanto ao caminho a trilhar durante o ensino. As bibliografias básicas e complementares são obras clássicas de suas áreas, ou seja, o PPC-NA analisado é bem fundamentado.

Diante da proposta inicial de romper com a dicotomia entre a teoria e a prática, de procurar contribuir para a formação de um professor de Matemática crítico e transformador, indicando, a importância da autonomia do professor, há indícios de que as transformações propostas evidenciam que o curso está trilhando um caminho para romper a barreira teoria-prática, também no que diz respeito às TDIC.

A pergunta que nos guiou foi: Como a unidade universitária de Nova Andradina organiza seu PPC diante dos avanços tecnológicos na educação? Concluímos, a partir da análise, que o PPC-NA está organizado de forma que o web currículo possa ser construído, principalmente com a distribuição da PCC em várias das disciplinas do curso, a partir da contribuição para uma visão crítica do licenciando quanto as novas tendências da Educação Matemática, incluindo a tecnologia, apesar das TDIC aparecerem poucas vezes explicitamente no PPC analisado há indícios de que o curso caminhe para viabilizar a criação de um web currículo.

\section{Agradecimentos}

Agradecemos a CAPES, pois, a pesquisa que subsidia este artigo tem apoio da Coordenação de Aperfeiçoamento de Pessoal de Nível Superior - Brasil (CAPES) - Código de Financiamento 001.

\section{Referências}

Abboud-Blanchard, M. (2014). Teachers and technologies: Shared constraints, common response. In: Clark-Wilson, A.; Robutti, O.; Sinclair, N. (Eds). The Mathematics Teacher in the Digital Era: an international perspective on technology focused professional development. Dordrecht: Springer.

Almeida, M. E. (2014). Integração currículo e tecnologias: concepção e possibilidades de criação de web currículo. Em Almeida, M. E.; Alves, R. M. \& Lemos, S. D. Web currículo: Aprendiaagem, pesquisa e conhecimento com o uso de tecnologias digitais (pp. 20-38). Rio de Janeiro: Letra Capital. https://issuu.com/letracapital/docs/web_curr_culo

Almeida, M. E., \& Valente, J. A. (2011). Tecnologias e currículo: trajetórias convergentes on divergentes? São Paulo: Paulus. 
Araújo, C. (2015). Identificando conbecimento tecnológico, pedagógico e de conteúdo de professores de Matemática em formação ao utilizar recursos multimídias. Campina Grande: (Dissertação) Universidade Estadual da Paraíba. http://tede.bc.uepb.edu.br/jspui/handle/tede/2327

Arroyo, M. G. (2013). Currículo, território em disputa (5 ed.). Petrópolis-RJ: Vozes.

Bogdan, R. C., \& Biklen, S. K. (1994). Investigação qualitativa em Educação. Portugal: Porto.

Brasil, Conselho Nacional de Educação. Conselho Pleno. (2015). Resolução CNE/CP n 02 de $1^{\circ}$ de julho de 2015. Brasília: Diário Oficial da União. portal.mec.gov/docman/agosto-2017-pdf/7031-res-cne-cp-00203072015-pdf/file

Cellard, A. (2008). A análise documental. Em J. ( POUPART, A pesquisa qualitativa: enfoques epistemológicos e metodológicos (pp. 295-316). Petropólis: Vozes.

Coutinho, C. P. (2011). TPACK: em busca de um referencial teórico para a formação de professores em Tecnologia Educativa. Revista Paidéi@. Acesso em 14 de abril de 2018, disponível em http://hdl.handle.net/1822/13670

Figueiredo, S. A. (2015). Formação inicial de professores e a integração da prática como componente curricular na disciplina de Matemática Elementar. [Tese, UNIAN]. https://docplayer.com.br/27922092-Universidadeanhanguera-de-sao-paulo-sonner-arfux-de-figueiredo.html

Fiorentini, D. et al. (2002). Fomação de professores que ensinam Matemática: um balanço de 25 anos de pesquisa brasileira. Educação em Revista - Dossiê Educação Matemática.

Gibbs, G. (2009). Análise de dados qualitativos. São Paulo: Artmed.

Gomes, I. R. P. (2016). Cidades pequenas e rede urbana: interações a partir do Sudoeste do estado de Mato Grosso do Sul-MS. [Dissertação, UFGD]. http://repositorio.ufgd.edu.br/jspui/handle/prefix/1434

Lopes, R. P. (2010) Formação para uso das Tecnologias Digitais de Informação e Comunicação nas licenciaturas das Universidades Estaduais Paulistas. $\quad$ [Dissertação, $\quad$ UNESP]. https://repositorio.unesp.br/handle/11449/92296

Nonato, K. J. (2011) Estágio Supervisionado em Matemática: Contribuições para a formação de professores de Matemática. [Dissertação, UFMS]. https://posgraduacao.ufms.br/portal/trabalhoarquivos/download/1831

Oliveira, W. A.; Nonato, K. J.; Ribeiro, V. M. \& Lobo da Costa, N. M. (2020) A pandemia e a urgência para os professores em construir novos conhecimentos. Em: Anais II CONVIBE-FROPRO. Rio Grande do Norte.

Sacristán, Jose G. (1998) Currículo: os conteúdos do ensino ou uma análise da prática? In: Sacristán, José G. \& Pérez Gomes, A. I. Compreender e transformar o ensino. Porto Alegre, RS: Artmed.

Sacristán, J. G. (2000). O Currículo: uma reflexão sobre a prática (3ª ed.). Porto Alegre, RS: Artmed. 
Santana, E. B.; Calixto, M. J. M. S. (2019) A centralidade do ensino superior e o processo de redefinição socioespacial em Nova Andradina-MS: apontamentos preliminares. Formação Online, 26[48], p. 52-70. https://revista.fct.unesp.br/index.php/formacao/article/view/5619

Severino, A. J. (2007). Metodologia do Trabalho Cientifico (23 ed.). São Paulo: Cortez.

Thompson, J. B. (2011). Ideologia e cultura moderna: teoria social crítica na era dos meios 1073 de comunicação de massa. 9 ed. Petrópolis, RJ: Vozes.

Universidade Estadual De Mato Grosso Do Sul. (2019) Projeto Pedagógico Matemática, Licenciatura. Nova Andradina (UEMS). Acesso em 15 de janeiro de 2020, disponível em http://www.uems.br

Universidade Estadual De Mato Grosso Do Sul. (2010). Projeto Político Pedagógico, Matemática. Nova Andradina (UEMS).

Valente, J. A. \& Almeida, F. J. (1997). Visão analítica da informática no Brasil: a questão da formação do professor. Florianópolis: Revista Brasileira de Informática na Educaşão. Sociedade Brasileira de Computação. http://www.geogebra.im-uff.mat.br/biblioteca/valente.html

Veiga, I. P. A. (1995). Projeto Político-Pedagógico da Escola: uma construção possível. Campinas: Papirus.

Viseu, F.; Leite, L. (2019). Developing technologically enhanced mathematics pedagogical content knowledge in initial teacher education. In: Daniela, L. Didactics of smart pedagogy: smart pedagogy for technology enhanced learning. Cham, Switzerland: Springer.

\section{Sobre as Autoras}

\section{KARLA JOCELYA NONATO}

iD ORCID: https://orcid.org/0000-0002-6206-2042

Doutoranda em Educação Matemática pela Universidade Anhanguera de São Paulo, Mestre em Educação Matemática e graduada em Matemática pela Universidade Federal de Mato Grosso do Sul. Professora Adjunta no Campus do Pantanal da Universidade Federal de Mato Grosso do Sul. Temas de pesquisa: Formação de professores e Educação Tecnológica.

E-mail:karlanonato@yahoo.com.br

\section{NIELCE MENEGUELO LOBO DA COSTA}

(iD) ORCID: https://orcid.org/0000-0003-4391-9730

Doutorado em Educação: Currículo pela Pontifícia Universidade Católica de São Paulo. Pós doutorado em Ciências da Educação, especialidade de Tecnologia Educativa. Mestre em Ensino da Matemática e Graduada em Matemática e Pedagogia. Professora do Programas de Pós-graduação em Educação Matemática e Coordenadora do Programa de Ensino de Ciências e Saúde da Universidade Anhanguera de São Paulo (Brasil). Temas de pesquisa: Formação de professores e Educação Tecnológica.

E-mail: nielce.lobo@gmail.com

Enviado em: 4 jan. 2021.

Aprovado em: 29 maio. 2021. 